\title{
Characteristics of Regional Cerebral Blood Flow in Alzheimer Disease and Amnestic Mild Cognitive Impairment by Single-Photon Emission Computerized Tomography: A Cross-Sectional Study
}

\author{
Yota Kunieda ${ }^{a, b}$ Chiaki Arakawac Takumi Yamadab Mizue Suzuki ${ }^{a}$ d \\ Shingo Koyamaa, ${ }^{d}$ Yosuke Kimura ${ }^{d}$ Takeo Ichikawad Shuhei Shino ${ }^{d}$ \\ Minoru Yamadad Ryuto Hirokawa ${ }^{e}$ Tadamitsu Matsuda $^{f}$ \\ Tomokazu Takakura ${ }^{a}{\text { Tomohide Adachig }{ }^{2} \text { Haruhiko Hoshino }}^{9}$

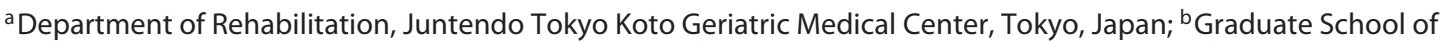 \\ Human Health Sciences, Tokyo Metropolitan University, Tokyo, Japan; ' Department of Internal Medicine, Musubiha

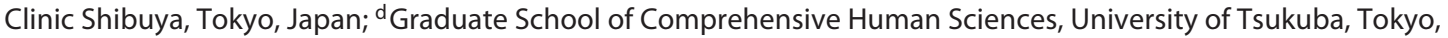 \\ Japan; ${ }^{\mathrm{e}}$ Department of Radiology and Nuclear Medicine, Akita Cerebrospinal and Cardiovascular Center, Akita, \\ Japan; ${ }^{\mathrm{D}}$ Department of Physical Therapy, Faculty of Health Sciences, Juntendo University, Tokyo, Japan; ${ }^{9}$ Dementia- \\ Related Disease Medical Center, Tokyo Saiseikai Central Hospital, Tokyo, Japan
}

\section{Keywords}

Alzheimer dementia · Regional cerebral blood flow · Mild cognitive impairment · Single-photon emission computerized tomography $\cdot$ Cross-sectional study

\begin{abstract}
Introduction: The regional cerebral blood flow (rCBF) distribution can affect brain functioning, leading to amnestic mild cognitive impairment ( $\mathrm{aMCl}$ ) and mild Alzheimer disease (AD). This study aimed to clarify the detailed characteristics of rCBF distribution in patients with mild AD and aMCI. Methods: This cross-sectional study from April 2015 to March 2018 included 103 older adults (mean age 78.9 years; 60\% females), out of a total of 302 adults, and categorized them into 3 groups according to cognitive symptoms. The normal control (NC), aMCl, and mild AD groups included 20,50, and
\end{abstract}

karger@karger.com www.karger.com/dee

Karger $\stackrel{\text { ' }}{5}$

BOPEN ACCESS
(C) 2021 The Author(s)

Published by S. Karger AG, Basel

This is an Open Access article licensed under the Creative Commons Attribution-NonCommercial-4.0 International License (CC BY-NC) (http://www.karger.com/Services/OpenAccessLicense), applicable to the online version of the article only. Usage and distribution for commercial purposes requires written permission.
33 participants, respectively. The primary outcome was $\mathrm{rCBF}$, which was compared among the 3 groups using a 2-sample $t$ test without correction for multiple comparisons. Results: In the $\mathrm{aMCl}$ group, the $\mathrm{rCBF}$ decreased in the bilateral parietal and left frontal association cortex and the bilateral premotor cortex $(p<0.01)$ but increased in the bilateral cerebellum $(p<0.01)$. In the mild AD group, the rCBF decreased in the bilateral parietal and occipital association cortex, the bilateral premotor cortex, the left temporal and frontal association cortex, and the left limbic lobe $(p<0.01)$. Conversely, the rCBF increased in some parts of the cerebellum, the bilateral frontal and temporal association cortex, the left occipital association cortex, and the right premotor cortex $(p<$ $0.01)$. Conclusion: Based on the analysis of the values obtained, it was inferred that the $\mathrm{rCBF}$ undergoes reduction and elevation in $\mathrm{aMCl}$ and $\mathrm{AD}$ patients.

(C) 2021 The Author(s)

Published by S. Karger AG, Basel
Correspondence to:

Yota Kunieda, kunieda.999@gmail.com 


\section{Introduction}

Single-photon emission computerized tomography (SPECT) has been increasingly employed for the diagnosis of functional alterations in the brain, resulting in mild cognitive impairment (MCI) or Alzheimer disease (AD) [1-3]; the extent of hypoperfusion on SPECT is greater than the atrophy on magnetic resonance imaging (MRI) [4]. Studies with SPECT have indicated the characteristics of the regional cerebral blood flow (rCBF) in older adults with MCI [5-9] or mild AD [9-17]. Consequently, specific areas, such as the posterior cingulate gyrus, the parietotemporal association cortex, and the medial temporal lobe, are regarded as the primary affected regions; however, the primary motor, sensory, and visual cortices are reported to be typically spared until the extremely severe stages [5]. However, these findings are yet to be established; the majority of such studies have been conducted in a relatively minor group of subjects $[9,12,13,15]$, with some analyzing exclusively those regions of the brain with a decreased $\mathrm{rCBF}[8,9,11,15,17]$.

The aim of the present study was to specify the characteristics of $\mathrm{rCBF}$ distribution in patients who have progressed to mild $\mathrm{AD}$ and amnestic MCI (aMCI) compared to typical older adults.

\section{Materials and Methods}

Study Design and Participants

The present cross-sectional study included 302 Japanese older adults who consulted the memory clinic of the Tokyo Saiseikai Central Hospital for a cognitive function examination from April 2015 to March 2018; cerebral blood flow was examined by SPECT. Out of 302 patients, 199 were excluded due to: age $<65$ years $(n=$ $10)$, stroke comorbidity $(n=6)$, tracers other than $99 \mathrm{mTc}-\mathrm{ECD}$ $(n=74)$, a non-AD dementia diagnosis based on National Institute of Neurological and Communicative Disorders and Stroke and Al-

Table 1. Clinical and demographic characteristics

\begin{tabular}{|c|c|c|c|c|c|c|}
\hline & Overall & $\mathrm{NC}$ & $\mathrm{aMCI}$ & Mild AD & $p$ value $^{\mathrm{a}}$ & $\begin{array}{l}\text { Post hoc } \\
\text { test }^{\mathrm{b}}\end{array}$ \\
\hline Subjects & 103 & 20 & 50 & 33 & & \\
\hline Age, years & $78.9 \pm 6.4$ & $74.9 \pm 6.0$ & $77.9 \pm 5.7$ & $82.8 \pm 5.8$ & $<0.001$ & $\mathrm{a}, \mathrm{b}$ \\
\hline Females & $60(58.3)$ & $15(75.0)$ & $24(48.0)$ & $21(63.6)$ & 0.088 & \\
\hline Education, years & $12(12-16)$ & $12.5(12-15.5)$ & $12(12-16)$ & $12(9-14)$ & 0.099 & \\
\hline \multicolumn{7}{|l|}{ Handedness } \\
\hline Right & $98(95.1)$ & $18(90.0)$ & $48(96.0)$ & $32(97.0)$ & 0.361 & \\
\hline Left & $1(1.0)$ & $1(5.0)$ & $0(0.0)$ & $0(0.0)$ & & \\
\hline Ambidextrous & $4(3.9)$ & $1(5.0)$ & $2(4.0)$ & $1(3.0)$ & & \\
\hline Household members (persons) & $2(1-2)$ & $2(1-2.8)$ & $2(1.8-2)$ & $2(1-2.5)$ & 0.758 & \\
\hline Living alone & $30(29.1)$ & $8(40.0)$ & $12(24.0)$ & $10(30.3)$ & 0.406 & \\
\hline \multicolumn{7}{|l|}{ Risk factors } \\
\hline Hypertension & $53(51.5)$ & $7(35.0)$ & $25(50.0)$ & $21(63.6)$ & 0.124 & \\
\hline Dyslipidemia & $36(35.0)$ & $9(45.0)$ & $17(34.0)$ & $10(30.3)$ & 0.543 & \\
\hline Diabetes mellitus & $31(30.1)$ & $4(20.0)$ & $16(32.0)$ & $11(33.3)$ & 0.543 & \\
\hline Atrial fibrillation & $10(9.7)$ & $1(5.0)$ & $7(14.0)$ & $2(6.1)$ & 0.358 & \\
\hline \multicolumn{7}{|l|}{ Comorbidities } \\
\hline Heart disease & $14(13.6)$ & $2(10.0)$ & $7(14.0)$ & $5(15.2)$ & 0.863 & \\
\hline Respiratory disease & $10(9.7)$ & $1(5.0)$ & $5(10.0)$ & $4(12.1)$ & 0.694 & \\
\hline Orthopedic disease & $15(14.6)$ & $1(5.0)$ & $9(18.0)$ & $5(15.2)$ & 0.376 & \\
\hline Kidney disease & $9(8.7)$ & $2(10.0)$ & $3(6.0)$ & $4(12.1)$ & 0.612 & \\
\hline Mental illnesses & $5(4.9)$ & $3(15.0)$ & $1(2.0)$ & $1(3.0)$ & 0.062 & \\
\hline VSRAD z-score & $1.34(0.93-2.13)$ & $1.17(0.82-1.37)$ & $1.16(0.81-1.70)$ & $2.15(1.17-3.21)$ & ) $<0.001$ & $a, b$ \\
\hline MMSE points & $26(23-28)$ & $29(27-29.8)$ & $27(26-28)$ & $22(21-24)$ & $<0.001$ & $a, b, c$ \\
\hline Anti-dementia medication (yes) & $34(33.0)$ & $0(0.0)$ & $4(8.0)$ & $30(90.9)$ & $<0.001$ & $\mathrm{a}, \mathrm{b}$ \\
\hline Donepezil & $17(16.5)$ & $0(0.0)$ & $0(0.0)$ & $17(51.5)$ & $<0.001$ & $\mathrm{a}, \mathrm{b}$ \\
\hline Galantamine & $7(6.8)$ & $0(0.0)$ & $3(6.0)$ & $4(12.1)$ & 0.225 & \\
\hline Rivastigmine & $9(8.7)$ & $0(0.0)$ & $1(2.0)$ & $8(24.2)$ & $<0.001$ & $\mathrm{a}, \mathrm{b}$ \\
\hline Memantine & $1(1.0)$ & $0(0.0)$ & $0(0.0)$ & $1(3.0)$ & 0.343 & \\
\hline
\end{tabular}

Values are presented as means $\pm \mathrm{SD}$, medians (IQR), or numbers $(\%) .{ }^{a}$ ANOVA, Kruskal-Wallis test, or $\chi^{2}$ test. ${ }^{b}$ Bonferroni test, $p<0.05$. a, NC vs. mild AD; b, aMCI vs. mild AD; c, NC vs. aMCI. 
Table 2. Brain regions showing a decreased $\mathrm{rCBF}$

\begin{tabular}{|c|c|c|c|c|c|c|}
\hline Association cortex & Regions & Side & BA & $\begin{array}{l}\text { MNI coordinates } \\
(\mathrm{x}, \mathrm{y}, \mathrm{z})\end{array}$ & $t$ value & $p$ value \\
\hline \multicolumn{7}{|c|}{ In the aMCI group compared to the $N C$ group } \\
\hline Frontal association cortex & Inferior frontal gyrus & $\mathrm{L}$ & 47 & $-50,22,-8$ & 3.05 & 0.002 \\
\hline \multirow[t]{2}{*}{ Premotor cortex } & Superior frontal gyrus & $\mathrm{R}$ & 6 & $2,26,66$ & 3.63 & $<0.001$ \\
\hline & Middle frontal gyrus & $\mathrm{L}$ & 6 & $-26,26,62$ & 3.28 & 0.001 \\
\hline \multirow[t]{4}{*}{ Parietal association cortex } & Precuneus & $\mathrm{R}$ & 7 & $28,-48,46$ & 3.10 & 0.001 \\
\hline & Precuneus & $\mathrm{L}$ & 7 & $0,-34,46$ & 2.54 & 0.007 \\
\hline & Inferior parietal lobule & $\mathrm{R}$ & 40 & $68,-26,32$ & 2.47 & 0.008 \\
\hline & Inferior parietal lobule & $\mathrm{L}$ & 40 & $-38,-40,42$ & 2.61 & 0.006 \\
\hline \multicolumn{7}{|c|}{ In the mild AD group compared to the aMCI group } \\
\hline \multirow[t]{3}{*}{ Premotor cortex } & Precentral gyrus & $\mathrm{R}$ & 6 & $38,-12,62$ & 2.79 & 0.003 \\
\hline & Superior frontal gyrus & $\mathrm{R}$ & 6 & $16,20,64$ & 2.51 & 0.007 \\
\hline & Middle frontal gyrus & $\mathrm{L}$ & 6 & $-32,-2,58$ & 2.68 & 0.004 \\
\hline \multirow[t]{5}{*}{ Parietal association cortex } & Precuneus & $\mathrm{R}$ & 7 & $12,-82,48$ & 3.67 & $<0.001$ \\
\hline & Superior parietal lobule & $\mathrm{R}$ & 7 & $40,-54,58$ & 2.51 & 0.007 \\
\hline & Precuneus & $\mathrm{R}$ & 7 & $10,-50,46$ & 2.48 & 0.008 \\
\hline & Inferior parietal lobule & $\mathrm{L}$ & 40 & $-40,-48,54$ & 3.20 & 0.001 \\
\hline & Postcentral cyrus & $\mathrm{L}$ & 40 & $-40,-30,54$ & 3.05 & 0.002 \\
\hline \multirow[t]{3}{*}{ Temporal association cortex } & Inferior temporal gyrus & $\mathrm{L}$ & 37 & $-66,-54,-12$ & 3.24 & 0.001 \\
\hline & Middle temporal gyrus & $\mathrm{L}$ & 37 & $-56,-50,-10$ & 2.72 & 0.004 \\
\hline & Middle temporal gyrus & $\mathrm{L}$ & 21 & $-68,-50,-4$ & 2.89 & 0.002 \\
\hline \multirow[t]{2}{*}{ Occipital association cortex } & Cuneus & $\mathrm{R}$ & 18 & $18,-100,12$ & 2.61 & 0.005 \\
\hline & Middle occipital gyrus & $\mathrm{L}$ & 19 & $-46,-84,12$ & 3.17 & 0.001 \\
\hline Limbic lobe & Parahippocampal gyrus & $\mathrm{L}$ & 35 & $-28,-14,-22$ & 2.81 & 0.003 \\
\hline Others & Cuneus & $\mathrm{L}$ & - & $-20,-94,2$ & 2.43 & 0.009 \\
\hline \multicolumn{7}{|c|}{ In the mild AD group compared to the NC group } \\
\hline Frontal association cortex & Middle frontal gyrus & $\mathrm{L}$ & 46 & $-42,34,18$ & 2.77 & 0.004 \\
\hline \multirow[t]{2}{*}{ Premotor cortex } & Superior frontal gyrus & $\mathrm{R}$ & 6 & $12,26,64$ & 3.41 & 0.001 \\
\hline & Middle frontal gyrus & $\mathrm{L}$ & 6 & $-26,24,62$ & 3.39 & 0.001 \\
\hline \multirow[t]{5}{*}{ Parietal association cortex } & Inferior parietal lobule & $\mathrm{R}$ & 40 & $42,-50,58$ & 3.01 & 0.002 \\
\hline & Inferior parietal lobule & $\mathrm{L}$ & 40 & $-40,-46,48$ & 3.56 & $<0.001$ \\
\hline & Superior parietal lobule & $\mathrm{R}$ & 7 & $34,-58,50$ & 2.94 & 0.002 \\
\hline & Superior parietal lobule & $\mathrm{L}$ & 7 & $-34,-68,48$ & 3.19 & 0.001 \\
\hline & Precuneus & $\mathrm{L}$ & 7 & $-6,-68,36$ & 3.65 & $<0.001$ \\
\hline
\end{tabular}

MNI, Montreal Neurological Institute; L, left; R, right. Unpaired $t$ test in SPM8, uncorrected, covariate for age, $p<0.01$.

zheimer's Disease and Related Disorders Association (NINCDSADRDA) criteria [18] or the Fifth Edition of the Diagnostic and Statistical Manual of Mental Disorders (DSM-5) [19] $(n=55)$, a Mini-Mental State Examination (MMSE) [20] score $<20(n=24)$, non-aMCI $(n=1)$, and missing data $(n=27)$; the present study analyzed 103 older adults. The study participants were divided into the following 3 groups: normal control (NC), aMCI, and mild AD. The NC category included those diagnosed with age-related cognitive decline or impairment. The aMCI class included those diagnosed according to MCI criteria [21], brain imaging, and medical examination via an interview. The mild $\mathrm{AD}$ group included those diagnosed based on NINCDS-ADRDA criteria [18] or the DSM-5 [19]. The NC, aMCI, and mild AD groups included 20, 50, and 33 participants, individually.

\section{Study Measurements}

Patient demographic and clinical characteristics were retrospectively extracted from medical records. These included age, sex, years of education, handedness, number of household members, dementia medication after diagnosis, prevalence of risk factors and 
Fig. 1. Brain regions mapping a decreased rCBF in SPM8. SPM $t$ mapping was thresholded at an uncorrected $p<0.01$ at the voxel level. A voxel-based unpaired $t$ test covariated for age was used to identify voxels that differed significantly in the aMCI group compared to the NC group (a), the mild AD group compared to the aMCI group (b), and the mild AD group compared to the NC group (c), respectively. The most significant area was the right superior frontal gyrus (BA 6) in a, the right precuneus (BA 7) in $\mathbf{b}$, and the left precuneus (BA 7) in c, respectively. $R$, right; $L$, left.
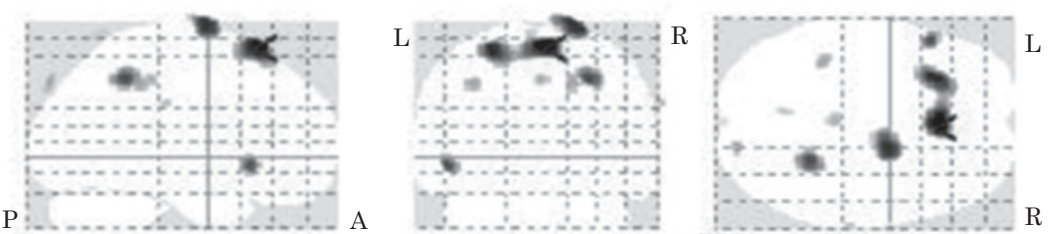

a In the aMCl group compared to the $\mathrm{NC}$ group
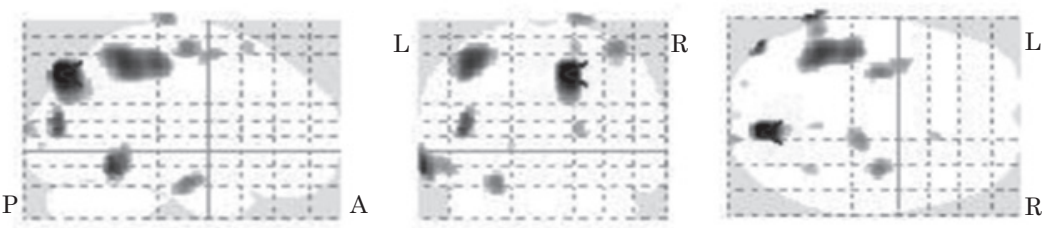

b In the mild AD group compared to the aMCI group
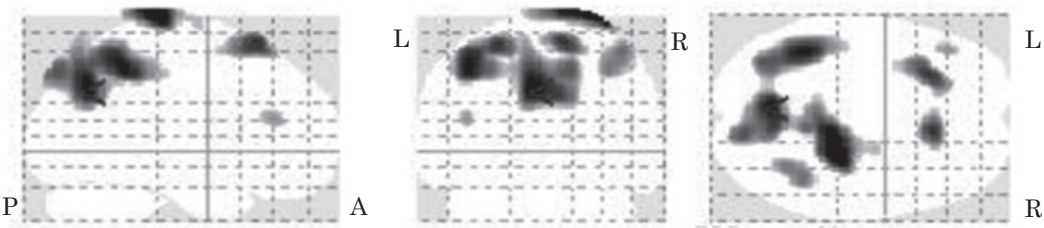

c In the mild AD group compared to the NC group comorbidities, z-scores based on the voxel-based specific regional analysis system for AD (VSRAD) to assess the degree of hippocampal atrophy $[7,22]$, and MMSE scores. $\mathrm{rCBF}$, as the primary outcome, was examined by SPECT.

\section{SPECT Evaluation}

All of the participants underwent SPECT imaging with radiopharmaceutical technetium-99 m ethyl cysteinate dimer $(99 \mathrm{mTc}$ ECD; Neurolite, Fujifilm RI Pharma, Tokyo, Japan) for measurement of the rCBF, injected with $600 \mathrm{MBq}$ of $99 \mathrm{mTc}-\mathrm{ECD}$ in a supine resting state. After $10 \mathrm{~min}$, neurological scanning was performed using an integrated SPECT/CT system (Discovery NM/CT 670 QSuite; GE Healthcare, Tokyo, Japan). The matrix and pixel sizes of the images were $64 \times 64$ and $5.89 \times 5.89 \mathrm{~mm}$, respectively. Tomographic 3-D reconstruction was performed using a filtered back projection algorithm (Butterworth filter order 10 with a cutoff frequency of 0.5 cycles $/ \mathrm{cm}$ ) and Chang attenuation correction [23]. A voxel-by-voxel group study was performed using Statistical Parametric Mapping version 8 (SPM8; Welcome Department of Cognitive Neurology, University College London, London, UK), running on R2013a (MATLAB 8.1; Mathworks, Inc., Sherborn, MA, USA). The images were spatially normalized by SPM8 to an original template for $99 \mathrm{mTc}$-ECD [24]. The data were standardized with the Montreal Neurological Institute atlas using a 12-parameter affine transformation, followed by nonlinear transfiguration and a trilinear interpolation. The dimensions of the resulting voxels were $2 \times 2 \times 2 \mathrm{~mm}$. The images were smoothened with a gaussian kernel as full width at half maximum of $12 \mathrm{~mm}$. The Montreal Neurological Institute coordinates were finally converted into Talairach values using the Talairach Daemon database.

\section{Statistical Analysis}

Statistical analysis was performed using SPSS version 21 (IBM Japan, Tokyo, Japan). The Shapiro-Wilk test assessed the normality of the clinical and demographic data. For group comparisons, continuous variables with a normal distribution were analyzed by ANOVA. Analysis of variables with a nonnormal distribution was performed using the Kruskal-Wallis test; categorical variables were analyzed using a $\chi^{2}$ test. The Bonferroni-adjusted $p$ value was used to assess differences in significance among groups. To compare $\mathrm{rCBF}$ in the SPM8, aMCI NC, and mild AD groups, an analysis was performed using the 2 -sample $t$ test (the general linear model at each voxel). Factors displaying significant differences between clinical and demographic characteristics were considered nuisance covariates. The significance of the $\mathrm{rCBF}$ was estimated at $p<0.01$, without correction for multiple comparisons $(T>2.38)$.

\section{Results}

The clinical and demographic characteristics are described in Table 1 . The mean $( \pm \mathrm{SD})$ age was $78.9 \pm 6.4$ years and the median MMSE score was 26 (IQR 23-28) points. Age and antidementia medications were significantly higher in the mild AD group compared to the NC and aMCI groups $(p<0.05)$; contrastingly, the VSRAD $\mathrm{Z}$-score was significantly lower for in the mild AD group $(p<0.05)$. Furthermore, significant differences in MMSE scores were observed $(p<0.05)$. 
Table 3. Brain regions showing an increased $\mathrm{rCBF}$

\begin{tabular}{|c|c|c|c|c|c|c|}
\hline Association cortex & Regions & Side & BA & $\begin{array}{l}\text { MNI coordinates } \\
(\mathrm{x}, \mathrm{y}, \mathrm{z})\end{array}$ & $t$ value & $p$ value \\
\hline \multicolumn{7}{|c|}{ In the aMCI group compared to the $N C$ group } \\
\hline Temporal association cortex & Inferior temporal gyrus & $\mathrm{L}$ & 37 & $-64,-60,-8$ & 3.25 & 0.001 \\
\hline \multirow[t]{2}{*}{ Occipital association cortex } & Cuneus & $\mathrm{R}$ & 18 & $28,-100,0$ & 3.00 & 0.002 \\
\hline & Fusiform gyrus & $\mathrm{R}$ & 19 & $36,-72,-8$ & 2.73 & 0.004 \\
\hline \multirow[t]{5}{*}{ Others } & Uvula & $\mathrm{R}$ & - & $18,-74,-32$ & 3.88 & $<0.001$ \\
\hline & Thalamus & $\mathrm{R}$ & - & $26,-22,6$ & 2.92 & 0.002 \\
\hline & Culmen & $\mathrm{R}$ & - & $44,-34,-26$ & 2.64 & 0.005 \\
\hline & Culmen & $\mathrm{L}$ & - & $-46,-38,-24$ & 3.83 & $<0.001$ \\
\hline & Inferior semi-lunar lobule & $\mathrm{L}$ & - & $-18,-68,-36$ & 3.73 & $<0.001$ \\
\hline \multicolumn{7}{|c|}{ In the mild AD group compared to the aMCI group } \\
\hline \multirow[t]{3}{*}{ Frontal association cortex } & Inferior frontal gyrus & $\mathrm{R}$ & 47 & $56,20,-4$ & 3.19 & 0.001 \\
\hline & Inferior frontal gyrus & $\mathrm{L}$ & 47 & $-52,24,-8$ & 2.56 & 0.006 \\
\hline & Middle frontal gyrus & $\mathrm{L}$ & 11 & $-28,36,-2$ & 2.40 & 0.009 \\
\hline Temporal association cortex & Superior temporal gyrus & $\mathrm{R}$ & 22 & $64,0,4$ & 2.61 & 0.005 \\
\hline \multicolumn{7}{|c|}{ In the mild AD group compared to the NC group } \\
\hline Frontal association cortex & Inferior frontal gyrus & $\mathrm{R}$ & 47 & $48,40,-18$ & 2.68 & 0.005 \\
\hline Premotor cortex & Middle frontal gyrus & $\mathrm{R}$ & 6 & $36,-4,44$ & 2.64 & 0.005 \\
\hline \multirow[t]{3}{*}{ Temporal association cortex } & Middle temporal gyrus & $\mathrm{R}$ & 37 & $62,-64,-2$ & 2.82 & 0.003 \\
\hline & Fusiform gyrus & $\mathrm{R}$ & 20 & $46,-34,-24$ & 2.86 & 0.003 \\
\hline & Fusiform gyrus & $\mathrm{L}$ & 20 & $-50,-32,-30$ & 3.51 & $<0.001$ \\
\hline Occipital association cortex & Middle occipital gyrus & $\mathrm{L}$ & 19 & $-58,-70,-4$ & 2.72 & 0.004 \\
\hline \multirow[t]{2}{*}{ Others } & Cerebellar lingual & $\mathrm{R}$ & - & $0,-48,-18$ & 3.56 & $<0.001$ \\
\hline & Inferior semi-lunar lobule & $\mathrm{L}$ & - & $-10,-68,-40$ & 3.60 & $<0.001$ \\
\hline
\end{tabular}

Unpaired $t$ test in SPM8, uncorrected, covariate for age, $p<0.01$. MNI, Montreal Neurological Institute; L, left; $\mathrm{R}$, right.

The brain regions with a decreased $\mathrm{rCBF}$ are shown in Table 2 and Figure 1.

- The aMCI group showed a reduction in the biparietal parietal and premotor cortex and the left frontal association cortices ( $p<0.01$, uncorrected) compared to $\mathrm{NC}$; the most significant one was in the right superior frontal gyrus (Brodman area [BA] 6; shown in Fig. 1a).

- The mild AD group demonstrated a decrease in the left temporal, bilateral parietal, occipital association, and premotor cortices, as well as the left limbic lobe $(p<$ 0.01 , uncorrected), compared to the aMCI group; the most important one was in the right precuneus (BA 7; shown in Fig. 1b).

- Compared to NC, the mild AD group indicated a decline in bilateral parietal association and the premotor cortex, as well as the left frontal association cortices $(p<0.01$, uncorrected); the most critical one was in the left precuneus (BA 7; shown in Fig. 1c).

The brain regions that showed an increased $\mathrm{rCBF}$ are indicated in Table 3 and Figure 2.
- Compared to the NC group, the aMCI group displayed elevation in certain areas in the bilateral cerebellum, as well as the left and the right occipital association cortices ( $p<0.01$, uncorrected); the most significant one was in the right uvula of the cerebellum (shown in Fig. 2a).

- In the mild $\mathrm{AD}$ group, rising $\mathrm{rCBF}$ levels were observed in specific areas of the bilateral frontal or right temporal association cortex $(p<0.01$, uncorrected $)$ compared to MCI; the most critical one was in the right inferior frontal gyrus (BA 47; shown in Fig. 2b).

- Compared to NC, the mild AD group displayed an increase in some of the cerebellum, the bilateral temporal cortex, the left occipital association cortex, the right frontal association, and the right premotor cortices $(p<0.01$, uncorrected); the most important one was in the left inferior semi-lunar lobule of the cerebellum (shown in Fig. 2c). 
Fig. 2. Brain regions mapping an increased rCBF in SPM8. SPM $t$ mapping was thresholded at an uncorrected $p<0.01$ at the voxel level. A voxel-based unpaired $t$ test covariated for age was used to identify voxels that differed significantly in the aMCI group compared to the NC group (a), the mild AD group compared to the aMCI group (b), and the mild $\mathrm{AD}$ group compared to the NC group (c), respectively. The most significant area was the right uvula at the cerebellum in a, right inferior frontal gyrus (BA 47) in b, and the left inferior semi-lunar lobule at the cerebellum in c, respectively. $\mathrm{R}$, right; $\mathrm{L}$, left.
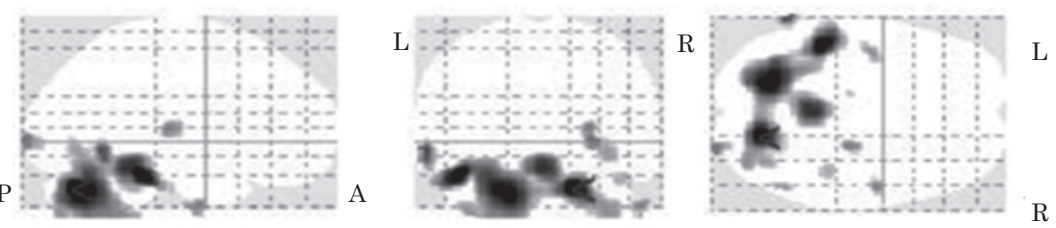

L

a In the aMCl group compared to the $\mathrm{NC}$ group
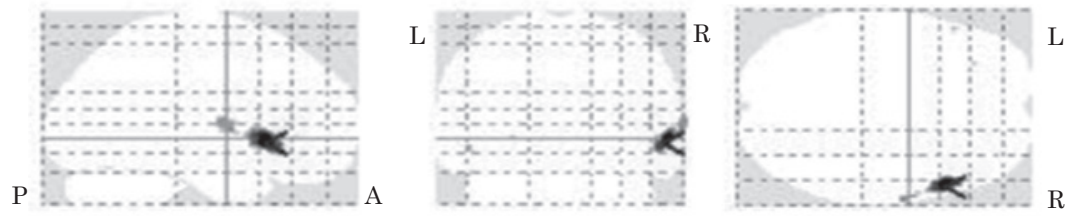

b In the mild $\mathrm{AD}$ group compared to the $\mathrm{aMCl}$ group
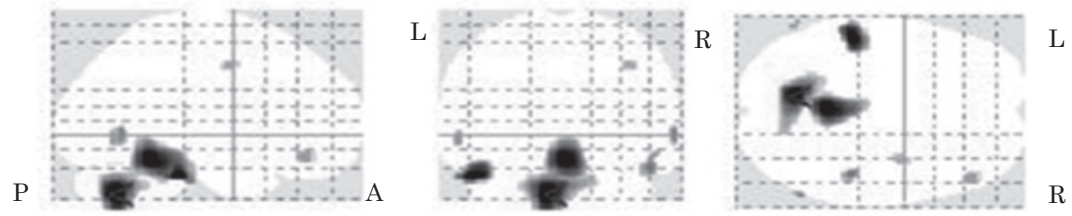

C In the mild AD group compared to the NC group

\section{Discussion}

The present retrospective cross-sectional study investigated the characteristics of $\mathrm{rCBF}$ in patients with $\mathrm{aMCI}$ and mild AD. This was detected to be lower in the bilateral premotor, parietal, and left frontal association cortices in the aMCI group compared to NC; higher values were observed in the bilateral cerebellum. Second, for mild AD, a reduction was seen in the bilateral parietal, premotor, left temporal, occipital, and frontal association cortices, as well as the left limbic lobe, compared to the aMCI and NC groups. Contrastingly, an elevation was seen in specific portions of the cerebellum and the bilateral frontal, right premotor, temporal, and left occipital association cortices.

The present investigation uncovered varying findings compared to previous studies. The present study showed decreased $\mathrm{rCBF}$ regions in the frontal lobe, such as the dorsal premotor and supplementary motor areas, in MCI patients; these are practically consistent with characteristics of $\mathrm{AD}$ patients [25]. Interestingly, attention deficit, especially executive control, may significantly contribute to the behavioral and cognitive deficits of aMCI [26], which are indicative of a decrease in $\mathrm{rCBF}$. This is consistent with the hypotheses of previous studies.

Some findings in the mild AD group and others were consistent with previous studies; however, others were not. Regions with a reduced $\mathrm{rCBF}$, such as the temporal, occipital, and frontal association cortices, in addition to the parietal cortex, extended to the entire brain [5]. Similarly, mild $\mathrm{AD}$ displayed increased $\mathrm{rCBF}$ regions in the cerebellum and prefrontal cortex; this was consistent with previous studies comparing values to those of NC [16, 27-30]. However, the integrated elevation and reduction in $\mathrm{rCBF}$, including the cerebral hemisphere, lacked uniformity with previous studies [31,32]. A significant increase in the cerebellum may cause a vanishing phenomenon, compensating for rCBF in the cerebral cortex [10] and possibly affecting aMCI or AD.

The present study has strengths and limitations. The recruited patients were classified as mild $\mathrm{AD}$, aMCI, or NC; both the decreased and elevated regions were considered for $\mathrm{rCBF}$. The findings of the present study suggest detailed characteristics in mild $\mathrm{AD}$ and aMCI, providing evidence for the establishment of an effective intervention method. Contrastingly, its limitation is its cross-sectional design; important indicators of rCBF, such as memory and executive function, were not considered in the present study. Therefore, the pathway of changes and the relationship with multiple cognitive functions are not precise. Further studies with a longitudinal cohort or a clinical trial design in multiple facilities are required to overcome these limitations. 


\section{Conclusion}

We observed the characteristics of changes in $\mathrm{rCBF}$ for patients with $\mathrm{aMCI}$ and $\mathrm{AD}$. The specified regions of reduced and elevated $\mathrm{rCBF}$ are novel findings of the present study. Furthermore, it is necessary to clarify the background of the participants, including the cause and clinical symptoms of $\mathrm{MCI}$ or $\mathrm{AD}$, and subsequently conduct a longitudinal clinical trial.

\section{Acknowledgement}

The authors thank the staff of the Tokyo Saiseikai Central Hospital and all of the participants for their cooperation with the present study. We are grateful to Mr. Naoharu Takemura and Mr. Tetsushi Miki of Fujifilm Toyama Chemical Co., Ltd. for their cooperation with image processing in brain SPECT. We would like to thank Editage (www.editage.com) for English language editing.

\section{Statement of Ethics}

The present study conformed to the ethical guidelines of the Declaration of Helsinki. The study protocol was reviewed and approved by the Ethics Committee of the Tokyo Saiseikai Central Hospital (approval No. 30-72).

\section{Conflict of Interest Statement}

The authors have no conflict of interests to declare.

\section{Funding Sources}

No specific grant from any funding agency or the commercial or not-for-profit sector was received for this study.

\section{Author Contributions}

Y. Kunieda, C. Arakawa, T. Yamada, M. Suzuki, S. Koyama, Y. Kimura, T. Ichikawa, S. Shino, and M. Yamada contributed to the study concept and design, analysis and interpretation of data, and elaboration of this paper. R. Hirokawa contributed to the acquisition of clinical and imaging data. T. Matsuda participated in the acquisition and analysis of data. T. Takakura, T. Adachi, and $\mathrm{H}$. Hoshino verified many aspects of this study and assisted in the preparation of this report. All of the authors approved the final version of this report.

\section{References}

1 Jack CR Jr. Alzheimer disease: new concepts on its neurobiology and the clinical role imagingwill play. Radiology.2012 May;263(2):34461.

2 Jack CR Jr, Knopman DS, Jagust WJ, Petersen RC, Weiner MW, Aisen PS, et al. Tracking pathophysiological processes in Alzheimer's disease: an updated hypothetical model of dynamic biomarkers. Lancet Neurol. 2013 Feb;12(2):207-16.

3 Morinaga A, Ono K, Ikeda T, Ikeda Y, Shima $\mathrm{K}$, Noguchi-Shinohara M, et al. A comparison of the diagnostic sensitivity of MRI, CBFSPECT, FDG-PET and cerebrospinal fluid biomarkers for detecting Alzheimer's disease in a memory clinic. Dement Geriatr Cogn Disord. 2010;30(4):285-92.

4 Murray AD. Imaging approaches for dementia. AJNR Am J Neuroradiol. 2012 Nov;33(10):1836-44.

5 Matsuda $\mathrm{H}$. Role of neuroimaging in $\mathrm{Al}$ zheimer's disease, with emphasis on brain perfusion SPECT. J Nucl Med. 2007 Aug;48(8):1289-300.
6 Imabayashi E, Matsuda H, Asada T, Ohnishi T, Sakamoto S, Nakano S, et al. Superiority of 3-dimensional stereotactic surface projection analysis over visual inspection in discrimination of patients with very early Alzheimer's disease from controls using brain perfusion SPECT. J Nucl Med. 2004 Sep;45(9):1450-7.

7 Matsuda $\mathrm{H}$. The role of neuroimaging in mild cognitive impairment. Neuropathology. 2007 Dec;27(6):570-7.

8 Niwa F, Kondo M, Sakurada K, Nakagawa M, Imanishi J, Mizuno T. Regional cerebral blood flow in [123]I-IMP single-photon emission computed tomography and the Wechsler Memory Scale-revised in nondemented elderly subjects with subjective cognitive impairment. Intern Med. 2016;55(24):3571-8.

9 Alegret M, Cuberas-Borrós G, Espinosa A, Valero S, Hernández I, Ruíz A, et al. Cognitive, genetic, and brain perfusion factors associated with four year incidence of Alzheimer's disease from mild cognitive impairment. J Alzheimers Dis. 2014;41(3):739-48.

10 Kogure D, Matsuda H, Ohnishi T, Asada T, Uno M, Kunihiro T, et al. Longitudinal evaluation of early Alzheimer's disease using brain perfusion SPECT. J Nucl Med. 2000 Jul;41(7):1155-62.
11 Hirao K, Ohnishi T, Hirata Y, Yamashita F, Mori T, Moriguchi Y, et al. The prediction of rapid conversion to Alzheimer's disease in mild cognitive impairment using regional cerebral blood flow SPECT. Neuroimage. 2005 Dec;28(4):1014-21.

12 Takahashi M, Tada T, Nakamura T, Koyama $\mathrm{K}$, Momose T. Efficacy and limitations of rCBF-SPECT in the diagnosis of Alzheimer's disease with amyloid-PET. Am J Alzheimers Dis Other Demen. 2019 Aug;34(5):314-21.

13 Bonte FJ, Tintner R, Weiner MF, Bigio EH, White CL 3rd. Brain blood flow in the dementias: SPECT with histopathologic correlation. Radiology. 1993 Feb;186(2):361-5.

14 Okamura N, Arai H, Maruyama M, Higuchi $\mathrm{M}$, Matsui T, Tanji $\mathrm{H}$, et al. Combined analysis of CSF tau levels and [(123)I]iodoamphetamine SPECT in mild cognitive impairment: implications for a novel predictor of Alzheimer's disease. Am J Psychiatry. 2002 Mar;159(3):474-6.

15 Alegret M, Cuberas-Borrós G, Vinyes-Junqué G, Espinosa A, Valero S, Hernández I, et al. A two-year follow-up of cognitive deficits and brain perfusion in mild cognitive impairment and mild Alzheimer's disease. J Alzheimers Dis. 2012;30(1):109-20. 
16 Johnson KA, Moran EK, Becker JA, Blacker D, Fischman AJ, Albert MS. Single photon emission computed tomography perfusion differences in mild cognitive impairment. J Neurol Neurosurg Psychiatry. 2007 Mar; 78(3):240-7.

17 Kikukawa T, Abe T, Ataka S, Saito H, Hasegawa I, Mino T, et al. Amyloid deposition and CBF patterns predict conversion of mild cognitive impairment to dementia. Neurol Sci. 2018 Sep;39(9):1597-602.

18 McKhann G, Drachman D, Folstein M, Katzman R, Price D, Stadlan EM. Clinical diagnosis of Alzheimer's disease: report of the NINCDS-ADRDA Work Group under the auspices of Department of Health and $\mathrm{Hu}$ man Services Task Force on Alzheimer's Disease. Neurology. 1984 Jul;34(7):939-44.

19 Sachdev PS, Blacker D, Blazer DG, Ganguli $M$, Jeste DV, Paulsen JS, et al. Classifying neurocognitive disorders: the DSM-5 approach. Nat Rev Neurol. 2014 Nov;10(11):634-42.

20 Tombaugh TN, McIntyre NJ. The mini-mental state examination: a comprehensive review. J Am Geriatr Soc. 1992 Sep;40(9):92235.
21 Petersen RC. Mild cognitive impairment as a diagnostic entity. J Intern Med. 2004 Sep; 256(3):183-94.

22 Hirata Y, Matsuda H, Nemoto K, Ohnishi T, Hirao K, Yamashita F, et al. Voxel-based morphometry to discriminate early Alzheimer's disease from controls. Neurosci Lett. 2005 Jul;382(3):269-74

23 Chang LT. A method for attenuation correction in radionuclide computed tomography. IEEE Trans Nucl Sci. 1978 Feb;25(1):638-43.

24 Ohnishi T, Matsuda H, Hashimoto T, Kunihiro T, Nishikawa M, Uema T, et al. Abnormal regional cerebral blood flow in childhood autism. Brain. 2000 Sep;123:1838-44.

$25 \mathrm{Li} \mathrm{R,} \mathrm{Wu} \mathrm{X,} \mathrm{Fleisher} \mathrm{AS,} \mathrm{Reiman} \mathrm{EM,} \mathrm{Chen} \mathrm{K,}$ Yao L. Attention-related networks in $\mathrm{Al}$ zheimer's disease: a resting functional MRI study. Hum Brain Mapp. 2012 May;33(5): 1076-88.

26 Van Dam NT, Sano M, Mitsis EM, Grossman HT, Gu X, Park Y, et al. Functional neural correlates of attentional deficits in amnestic mild cognitive impairment. PLoS One. 2013;8(1): e54035.
27 Braak H, Braak E. Neuropathological stageing of Alzheimer-related changes. Acta Neuropathol. 1991;82(4):239-59.

28 Thal DR, Rüb U, Orantes M, Braak H. Phases of A beta-deposition in the human brain and its relevance for the development of AD. Neurology. 2002 Jun;58(12):1791-800.

29 Thal DR, Griffin WS, Braak H. Parenchymal and vascular Abeta-deposition and its effects on the degeneration of neurons and cognition in Alzheimer's disease. J Cell Mol Med. 2008 Oct;12(5b 5B):1848-62.

30 Huang C, Wahlund LO, Almkvist O, Elehu D, Svensson L, Jonsson T, et al. Voxel- and VOIbased analysis of SPECT CBF in relation to clinical and psychological heterogeneity of mild cognitive impairment. Neuroimage. 2003 Jul;19(3):1137-44.

31 Reesink FE, García DV, Sánchez-Catasús CA, Peretti DE, Willemsen AT, Boellaard R, et al. Crossed cerebellar diaschisis in Alzheimer's disease. Curr Alzheimer Res. 2018;15(13): 1267-75.

32 Sagiuchi T, Ishii K, Asano Y, Aoki Y, Kikuchi $\mathrm{K}$, Jinguuji $\mathrm{K}$, et al. Interictal crossed cerebellar hyperperfusion on Tc-99m ECD SPECT. Ann Nucl Med. 2001 Aug;15(4):369-72. 